\begin{tabular}{llllll}
\hline Revista Iberoamericana. & Vol. LXV, Núm. 186, Enero-Marzo 1999; $185-187$ \\
\hline
\end{tabular}

\title{
ELENA GARRO UNA DE LAS MÁS GRANDES ESCRITORAS DE MÉXICO HA MUERTO (1916-1998)
}

\author{
POR \\ RHINA TORUÑo \\ The University of Texas of the Permian Basin
}

El periódico The New York Times ${ }^{1}$ informó de la muerte de Elena Garro el pasado 22 de agosto de 1998 en el hospital de Cuernavaca, víctima de un paro cardíaco ocurrido a raíz de un enfisema pulmonar. Fue una nota larga acompañada de una foto de Garro. El mismo día, en el periódico mexicano La Jornada (p. 1), el presidente del CNCA (Consejo Nacional de México para LaCultura y las Artes), el Licenciado Rafael Tovar y de Teresa, quien asistió a los funerales de Elena dijo: "Elena Garro es una de las tres más importantes escritoras que México ha producido desde el siglo XVII con Sor Juana Inés de la Cruz y Rosario Castellanos [...] México ha perdido a la escritora contemporánea más importante del siglo XX. El país ha perdido en Octavio Paz (Premio Nobel de literatura 1990, quien murió el pasado 19 de abril) y Elena Garro a sus dos mejores escritores, hoy de nuevo las letras mágicas están de luto y por ello hay que guardar un minuto de silencio".

Elena Garro nació en Puebla de los Angeles, que queda a 75 millas de la ciudad de México, el 11 de diciembre de 1916. ${ }^{2}$ En 1937 se casó Elena con Octavio Paz. Meses después viajaron juntos a España para asistir al Congreso de Intelectuales Antifascistas, en medio de la guerra civil española. En Memorias de España: 1937 (1992) y también en la novela La casa junto al río está expresada la opinión de Garro sobre ese momento trágico de España, añadiendo también algunos datos biográficos.

En 1958 publicó su primer libro Un hogar sólido, un volumen de doce obras de teatro. En 1960 La señora en su balcón, en la Tercera Antología de obras de teatro en un acto (México, Colección Teatro Mexicano). En 1963 publicó Los recuerdos del porvenir, su primera novela. Escrita diez años antes. Esta novela, recibió el premio "Xavier Villaurrutia"

\footnotetext{
'En su edición vespertina del 25 de agosto de 1998. Sección B; p. 7; columna 1, autor Anthony De Palma.

${ }^{2}$ En todas las antologías que se refieren a ella, dan como la fecha de su nacimiento 1920 , incluso en la nota necrológica se da esa fecha, sin embargo cuando la visité por última vez, el 24 de abril de año recién pasado, 1998, después de la muerte de Octavio Paz, le pregunté si se recordaba la fecha exacta de su nacimiento y me dijo que sí, que era 1916. Nació de madre mexicana oriunda de la entidad federativa de Chihuahua, Eperanza Navarro, y padre español José Antonio Garro. En la novela Un traje rojo para este duelo (1996) por cierto es la única novela donde la narradora es la hija de la escritora. En esta novela hay referencias biográficas al padre de Garro cuando se estaba muriendo, a la madre de Octavio como la abuela de Pili, también a la relación entre Octavio, Elena y la hija de ambos, Helena Paz Garro.
} 
el mismo año de su publicación. Ha sido traducida al inglés: Recollections of Things to Come por Ruth L. C. Simms de la Universidad de Austin. Publicada por la Editorial de la Universidad de Texas. Al francés: La Fete á Ixtepec, traducida por Alice Gascar y publicada en París por Stock. ${ }^{3}$

Después de esa novela, Garro siguió escribiendo, aunque no todo se publicó en esos años: "Nuestras vidas son los ríos" en La palabra y el hombre (Xalapa, Veracruz, 25 eneromarzo 1963: 123-30). La semana de colores, libro de cuentos (Xalapa, Universidad Veracruzana, 1964). Escribió la obra de teatro documental Felipe Angeles que se publicó hasta 1979 por la Universidad Nacional Autónoma de México. También escribió el manuscrito de la novela Testimonios sobre Mariana, 1965, que se publicó hasta 1981 por la editorial Grijalbo. No hay que olvidar la costumbre que tenía Garro de guardar sus manuscritos en sus famosos baúles y que esperasen 15,20 , hasta 40 años a que viniese a París una mano amiga como la de Emilio Carballido o Emanuel Carballo y desenterrasen los manuscritos y los llevasen a México para su publicación. Las novelas cortas que están siendo publicadas últimamente, Mi primer amor, Busca mi esquela, Un corazón en un bote de basura esperaron cuarenta años para ver la luz de la publicidad en la ciudad de México, en 1996. Mi hermanita Magdalena, salió publicada en diciembre de 1999 por ediciones Castillo, en Monterrey.

Elena Garro vivió la mayor de su tiempo en el extranjero, especialmente en Francia, España, Suiza, Alemania, como también dos años en Estados Unidos y unos meses en Japón. Esto explica los diferentes ambientes en sus novelas. Por ejemplo, se desarrollan en París: Testimonios sobre Mariana (1981), Reencuentro de personajes (1982), Inés (1995) y Un corazón en un bote de basura (1996). Un transfondo de la España fascista se detecta en $L a$ casajunto al río (1983), y en el libro autobiográfico Memorias de España (1992), que relata la relación de Octavio Paz y Elena Garro recién casados (se desarrolla en Madrid y también en París). Todas sus obras de teatro, como también las tres últimas novelas, tienen como escenario la ciudad de México, Un hogar sólido (1958), La mudanza (1959), La señora en su balcón (1960), El árbol (1963), La dama boba (1964), Felipe Angeles (1979). Ya en su primera novela Los recuerdos del porvenir (1963) y en sus libros de cuentos La semana de colores (1964) también en los libros de ensayos periodísticos Los revolucionarios mexicanos (1977) y las últimas novelas publicadas hasta la fecha Y Matarazo no llamó ... (1989), Un traje rojo para este duelo (1996), Busca mi esquela y Primer amor (1996), Un corazón en un bote de basura (1996).

\footnotetext{
${ }^{3}$ También me dijo Elena (en julio de 1997) que está traducida al alemán y al polaco, en estos momentos se está traduciendo al nahualt. Carlos Fuentes, en un nota necrológica aparecida en el periódico $L a$ reforma comentó la repercusión internacional de esta novela. Recuerdo que después del Congresohomenaje a Elena Garro que le organizamos la Dra. Luz Elena Gutiérrez de Velasco, coordinadora del PIEM (Programa de estudios Interdisciplinarios de Estudios de la Mujer) de El Colegio de México y quien estas letras escribe, en julio de 1997, la investigadora alemana Veronica Beuker, que está traduciendo la obra de Garro al alemán, le preguntó por qué su novela Los recuerdos del porvenir no forma parte de las novelas del Boom latinoamericano; Elena Garro respondió: "porque se escribió siete años antes, porque se consideró católica (esta novela presenta un aspecto de la Revolución Mexicana: la guerra de los Cristeros) y también porque soy mujer".
} 
Elena Garro dejó de existir, pero sus novelas, sus obras de teatro, cuentos y sus poesías que todavía se mantienen inéditas, como también sus conversaciones grabadas en tocacintas permanecen con vida. El legado que nos deja especialmente a los/las latinoamericanos/as es fuerte. La pluma fue su arma más potente, pero no fue la única. Ella personalmente abogó por los campesinos en los tribunales de justicia. Ella luchó contra las injusticias de nuestro mundo latinoamericano en sus diversas manifestaciones. 
